\title{
INTRODUCTION: INTERNATIONAL CONFERENCE SPECIAL ISSUE
}

\author{
P. David Marshall deakin University AND Kim Barbour University of Adelaide
}

Scholarship and academic enquiry are complex entities. Individuals sequester themselves to complete their projects, publications, and manuscripts, and this solo activity can make us collectively think that the ivory tower of academic life is real. But the real hub of research, and its genuine success, is built from the process of exchange: conversations, discussions, engagements, re-readings and - building from this activity - amendments and integration of other related ideas, concepts, and trials. This journal has built from these exchanges as are the scholarly and academic personas (Barbour \& Marshall 2012; Marshall, Barbour \& Moore 2018) that we enact to present and perform our work: we depend on this "verkehr" (Marx \& Engels 1970 ) to both advance our ideas and to ensure that those ideas (and our professional identities) have some impact and value.

This issue has been directly built from these exchanges, collaborations, and discussions. Persona Studies the journal, and persona studies the field, held its first major International Conference on the $25^{\text {th }}$ and $26^{\text {th }}$ of June 2019 , hosted by Newcastle University in Newcastleupon-Tyne UK and led by Dr Bethany Usher and a team of NU scholars and supporters. The papers in this special issue have emerged from this inaugural conference, building from an elaborate interchange among scholars from original abstracts for the conference, questions and queries generated by an engaged audience, informal discussions at wonderfully catered lunches, dinners, and drinks throughout the conference, to follow-up re-iterations and amended texts that were read and reviewed once again with further prompts for elaborations and development and final submissions.

We have to admit that we (Kim and David) were overjoyed by this conference, building the research culture of persona studies significantly further. We could see the level of engagement of all who attended, and the desire and intentions enveloped collectively in their works and participation. The Conference's Final Discussion session, entitled Where next for persona studies, is a presage of future directions: this issue provides the beginnings of that intellectual journey. That conversation pointed to what we have both found most interesting and engaging in investigating persona: is the flexibility of the concept, its capacity to be taken up and utilised in unexpected ways. We sincerely hope that others continue to take this work in new, diverse, and challenging directions.

We want to also congratulate the team, led by Bethany Usher, who pulled this together during perhaps one of the most difficult years for collaborative scholarship. The launch of the new Perspectives section sees Usher, along with Darren Kelsey, Gareth Longstaff, and Elisa Kannasto explore new directions for the field in short form (around 1000 words); this is an exciting new space, and we look forward to both seeing the ideas proposed here develop, and see what else is pitched in this section (open for rolling submissions across the year as well as themed contributions). In the full-length article section, we have four papers emerging from the conference, beginning with Giles' fascinating and detailed examination of the path of persona studies to date. This is followed by three papers that explore particular personas of public figures, whether fictional or non-fictional. Helena Bassil-Morozow uses the concept of a trickster persona to explore Fleabag, drawing on ideas from Jung and socially acceptable femininity to 
unpack the impact and value of Phoebe Waller-Bridge's award-winning character and show. Samiran Culbert turns his attention to another landmark character, that of the 'Blackstar', examining how David Bowie's final persona was produced by himself, by the music industry, and by fans, and how fans used this persona in their mourning of Bowie on Reddit. Collaborative persona production continues in Nicholas Qyll's analysis of the many personas of Madonna, focusing particularly in this case on the visual components that make up her brand. Finally, Chris Miles draws together the Jungian perspective of Bassil-Morozow and the branding focus of Qyll to see what these two can offer both persona studies and marketing. To round out the issue, we are delighted to finally be able to publish a wonderful exploration of the Facebook personas of Modernist authors by Will Best. This paper ties together literary studies with online culture and persona studies in a deft and useful way in our open submissions section.

Publishing this issue is a substantial achievement. This year, when so many of us were forced away from the casual interactions and informal collaborations had in office buildings, we have had to become intentional in engaging with our colleagues while also managing the complexity of working from home and sharing workspaces with partners, housemates, and children. In some ways, this has brought us together with colleagues living in similar circumstances across the world, and it has been heartening to see the collective solidarity across the tertiary sector as we deal with online teaching, cancelled or reorganised conferences, timezone challenges, health concerns, massive job losses, political disruption, and the opportunity cost of such a tremendously disruptive year. These struggles were real, and have real impact on our scholarship and publishing schedules - we are so pleased to help these nine scholars have these fantastic papers published (just) within the bounds of 2020 - and our international collective solidarity needs to continue for years to come.

In this vein, we hope to host an online conference in the third quarter of 2021, likely spread over a month or so, with a series of weekly webinars and live discussions to support prerecorded video and podcast presentations. We have been eagerly watching and engaging in the experimental sessions run by many more established conferences this year, and plan on learning from these experiences in building a collaborative, interactive, and rewarding space for scholarly exchange. Confirmed details and a call for submissions will be circulated in early 2021 .

We also wish to thank the professional staff at Deakin University who support the journal, particularly Josipa Crnic and the IT team, for their work in upgrading the journal website and ensuring the look and feel of the site is functional and contemporary. Our archive of issues is there, as is our continued commitment to open access publishing without cost to author or reader, but both of these rest on the hard work and support of these professional colleagues. Thank you.

\section{REFERENCES:}

Barbour, K \& Marshall, PD 2012. The academic online constructing persona. First Mondays [Online], 17, available from:

<http://firstmonday.org/ojs/index.php/fm/article/viewArticle/3969/3292>.

Marshall, PD, Barbour, K \& Moore, C 2018. 'Academic persona: The construction of online reputation in the modern academy', in: Lupton, D, Mewburn, I \& Thomson, P (eds.) The Digital Academic: Critical Perspectives on Digital Technologies in Higher Education, London, Routledge.

Marx, K \& Engels, F 1970. The German Ideology, New York, International Publishers Co. 